P Bach

$J$ Jett

U Pastorino

M Tockman

S Swensen

C Begg

\section{Rastreio com tomografia computorizada e resultados no cancro do pulmão}

\author{
Computed tomography screening and lung cancer \\ outcomes
}

\section{Resumo}

Estima-se que o cancro do pulmão contribui em cerca de $6 \%$ para todas as causas de mortalidade anual, segundo dados estatísticos americanos ${ }^{1}$.

A procura de um método de rastreio eficaz nos indivíduos de alto risco faz assim todo o sentido.

Estudos prévios randomizados utilizando a radiografia de tórax no rastreio do cancro do pulmão não apoiam a utilização deste exame, dado que, apesar da detecção adicional de tumores ressecáveis e potencialmente curados, não reduziu o número de casos em estádio avançado nem a mortalidade por cancro do pulmão ${ }^{2}$.

A tomografia computorizada (TC) de baixa dose permite uma imagem de baixa resolução de todo o tórax obtida numa única inspiração com baixa exposição a radiação. $\mathrm{O}$ entusiasmo crescente desta técnica como método de rastreio justifica vários estudos observacionais já efectuados e a existência de estudos randomizados e controlados em curso; contudo, o rastreio por TC assenta nas mesmas premissas de imagem da radiografia de tórax.

A controvérsia entre a eficácia na detecção precoce e cura de estádios iniciais mas a não eficácia na redução do número de casos em estádio avançado e da mortalidade conduz a opiniões opostas quanto à proposta clínica da TC no despiste de cancro do pulmão nos indivíduos em risco.
O presente estudo longitudinal foi efectuado em três centros, dois nos EUA e um em Itália, e propôs-se comparar o número esperado com o número observado de novos casos de cancro do pulmão; de casos com indicação para terapêutica cirúrgica; de casos diagnosticados em estádio avançado e de mortalidade. O estudo avaliou 3246 indivíduos assintomáticos com idades compreendidas entre os 50 e 80 anos, fumadores ou ex-fumadores, submetendo-os a TC anual e abordagem diagnóstica e terapêutica nos casos de detecção de nódulos. A duração média dos três estudos foi de 3,9 anos. Os resultados encontrados foram comparados com modelo previamente validado para indivíduos de risco com idade entre os 50 e 80 anos, fumadores durante 25-60 anos com média de 10 a 60 cigarros por dia e com hábitos tabágicos actuais ou nos últimos 20 anos. Os dados combinados dos três grupos estudados revelaram:

- O diagnóstico de novos casos de cancro do pulmão foi superior ao que seria de esperar na ausência de rastreio - 144 casos contra 44,5 esperados.

- O número de cirurgias efectuadas foi também muito superior ao esperado - 109 casos contra 10,9 esperados.

- A detecção precoce de cancro do pulmão não reduziu o número de casos diagnosticados em estádio avançado - 42 casos contra 33,4 esperados.

JAMA 2007; 297:953-61. 
- A mortalidade por cancro do pulmão também não foi inferior nos casos submetidos a rastreio - 38 casos contra 38,8 esperados.

O rastreio com TC de baixa dose aumentou o número de casos diagnosticados de cancro do pulmão, e consequente terapêutica cirúrgica. Contudo, o mesmo rastreio não diminuiu o risco de diagnóstico em estádio avançado ou de morte por cancro do pulmão. É esta a conclusão dos autores, que aconselham que, até dados mais conclusivos de estudos randomizados em curso, os indivíduos de risco mas assintomáticos não têm indicação para ser submetidos a rastreio.

\section{Comentário}

O resultado deste estudo não difere do encontrado em estudos prévios com radiografia de tórax, conforme referido.

A controvérsia deste e dos outros resultados tem levado a tentativas várias de explicação do facto.

Alguns autores (os actuais também mencionam essa hipótese) apontam como possível explicação a hipótese de os nódulos diagnosticados em estádio precoce terem um carácter indolente, não evoluindo com o comportamento habitual da neoplasia do pulmão diagnosticada clinicamente.

Esta hipótese seria reforçada pelo facto de o número de cancros diagnosticados exceder o número preditivo não só no primeiro ano, mas em cada ano do rastreio, sugerindo um pool de pequenos nódulos indolentes apenas diagnosticados pela imagiologia. Além disso, não se verifica redução das neoplasias em estádios avançados, que seria de esperar se estas correspondessem à evolução natural dos nódulos entretanto tratados.

Os autores salientam a morbilidade das técnicas diagnósticas e terapêuticas de nódulos de eventual evolução lenta e realçam os riscos de exposição cíclica a radiações da técnica de rastreio em causa.
Contudo, a ausência de grupo de contolo, mas apenas um modelo preditivo é questionável.

Também questionável é a divisão entre neoplasia indolente/agressiva.

Admitindo-se casos de evolução lenta, será que o tempo de duração do estudo não foi suficiente para se detectar redução da mortalidade e dos casos avançados?

O confronto desta dúvida com o facto de um maior número de neoplasias serem detectadas e operadas leva, por parte de outros autores $^{3,4}$, a opiniões divergentes e à proposta de rastreio nos indivíduos em risco .

\section{Mensagem}

Os resultados dos estudos de rastreio de cancro do pulmão por técnicas de imagem, incluindo a TC de baixa dose são controversos, levantando dúvidas quanto à sua implementação.

Estudos randomizados e controlados, nomeadamente o National Lung Screening Trial, encontram-se em curso e poderão esclarecer estas dúvidas. Mas os primeiros resultados apenas estarão disponíveis em 2009. 


\section{Bibliografia}

1. Ries L, et al. SEER Cancer Statistics Review, 1973-1997. National Cancer Institute, 2000.

2. Bach P, et al. Screening for lung cancer: a review of the current literature. CHEST 2003;123:72s-82s

3. Henschke c, et al. Survival of patients with stage I lung cancer detected on CT screening. N Engl J Med 2006; 355:1763-71.
4. Lee T, et al. Direct-to-consumer marketing of high-technology screening tests. N Engl J Med 2002; 346:529-31.

Maria de Lurdes Carvalho 07.09 .03 